\title{
Biologic Treatments for Asthma and Chronic Obstructive Pulmonary Disorder
}

\author{
Misa Kusumoto $^{1}$ (D) and Bryan J. Mathis ${ }^{2, *(D)}$ \\ 1 University of Tsukuba School of Medicine, 1-1-1 Tennodai, Tsukuba, Ibaraki 305-8575, Japan; \\ misa.kusumoto126@gmail.com \\ 2 International Medical Center, University of Tsukuba Affiliated Hospital, 2-1-1 Amakubo, Tsukuba, \\ Ibaraki 305-8576, Japan \\ * Correspondence: bmathis@md.tsukuba.ac.jp; Tel.: +81-29-853-3004
}

\section{check for}

updates

Citation: Kusumoto, M.; Mathis, B.J. Biologic Treatments for Asthma and Chronic Obstructive Pulmonary Disorder. Allergies 2021, 1, 92-107. https://doi.org/10.3390/allergies1020007

Academic Editor: Pierre Rougé

Received: 2 March 2021

Accepted: 5 April 2021

Published: 6 April 202

Publisher's Note: MDPI stays neutral with regard to jurisdictional claims in published maps and institutional affiliations.

Copyright: (c) 2021 by the authors. Licensee MDPI, Basel, Switzerland. This article is an open access article distributed under the terms and conditions of the Creative Commons Attribution (CC BY) license (https:// creativecommons.org/licenses/by/ $4.0 /)$.

\begin{abstract}
The global COVID-19 pandemic has brought respiratory disease to the forefront of public health, but asthma prevalence has been rising globally for decades. Asthma is mediated by errant immune activation and airway remodeling, but the influences of environment, nutrition, and comorbidities (e.g., asthma-chronic obstructive pulmonary disorder-overlap [ACO]) are still poorly understood. Even as a new generation of biologic-based treatments offer better airway control and reductions in mortality, a lack of prophylactic treatments and mechanistic understanding complicates efforts to prevent pathogenesis. This review will explicate and synthesize current knowledge on the effect of ACO and biologics (omalizumab, mepolizumab, reslizumab, benralizumab, and dupilumab) on pathogenesis, treatment, and prognosis.
\end{abstract}

Keywords: asthma; prevalence; biologic; ACO; IL-5

\section{Introduction}

Asthma is an endemic disease, affecting over 339 million children and adults worldwide according to the World Health Organization, and industrialized countries are not exempt, as evidenced by Japan where, in 2017, over 1 million people in Japan were newly diagnosed with asthma [1]. Of these, 427,000 were under the age of 15 and diagnosis rates year-on-year have been climbing since 1984 [2]. Treatment is symptomatic and effective cures and prevention measures have not been reported in spite of advancements in immunology. Over the last 20 years, multiple advancements in immunosuppressive treatment have appeared, yet the prevalence of this incurable disease has climbed steadily, particularly in children. Numerous causes, from inheritance to allergies to industrial pollution, have been considered as key triggers for disease pathogenesis but the incredible diversity of responses inherent to the immune system confounds efforts to pin the blame on a single source. For this reason, we here will briefly review the current body of knowledge on asthmatic mechanisms, known/putative causes, environmental influence, standard treatments, newly developed biologic treatments, and overlap with chronic obstructive pulmonary disease (COPD). It is our opinion that targeted biologics will have the greatest impact on asthma treatment in the next 10 years and, if it cannot be prevented, then targeted therapies will provide the highest levels of control with the least side effects.

\subsection{Asthma Characteristics}

Allergic asthma is a chronic inflammatory disease of the lungs and airway that causes symptoms such as wheezing, breathlessness, coughing and chest tightness [3]. It is classified phenotypically and these categories have been extensively reviewed [4]. Allergic asthma is further subclassified according to the component of inflammatory cells in the sputum such as eosinophilic, neutrophilic, mixed granulocytic, and paucigranulocytic phenotypes [5]. These errant Type 2 immune responses manifest into three phenotypes: 
eosinophilic inflammation, IgE antigen-specific, and airway hyperresponsiveness $[5,6]$. (Figure 1) The role of histamine in the pathology and exacerbation of these types of asthma has been well studied and reviewed $[7,8]$. Although asthma can also be grouped according to genotype, the most common types are thought to be molecularly mediated through environmental or immune microenvironmental cues $[9,10]$. Regardless of type, the common manifestation of an asthma attack is characterized by chronic inflammation of the airway, leading to hyper-responsiveness and remodeling of the respiratory tract [3]. However, phenotypic manifestations may differ as adult asthma is evidenced by mucosal and sputum neutrophil infiltration whereas juvenile asthma is associated with atopy [3].

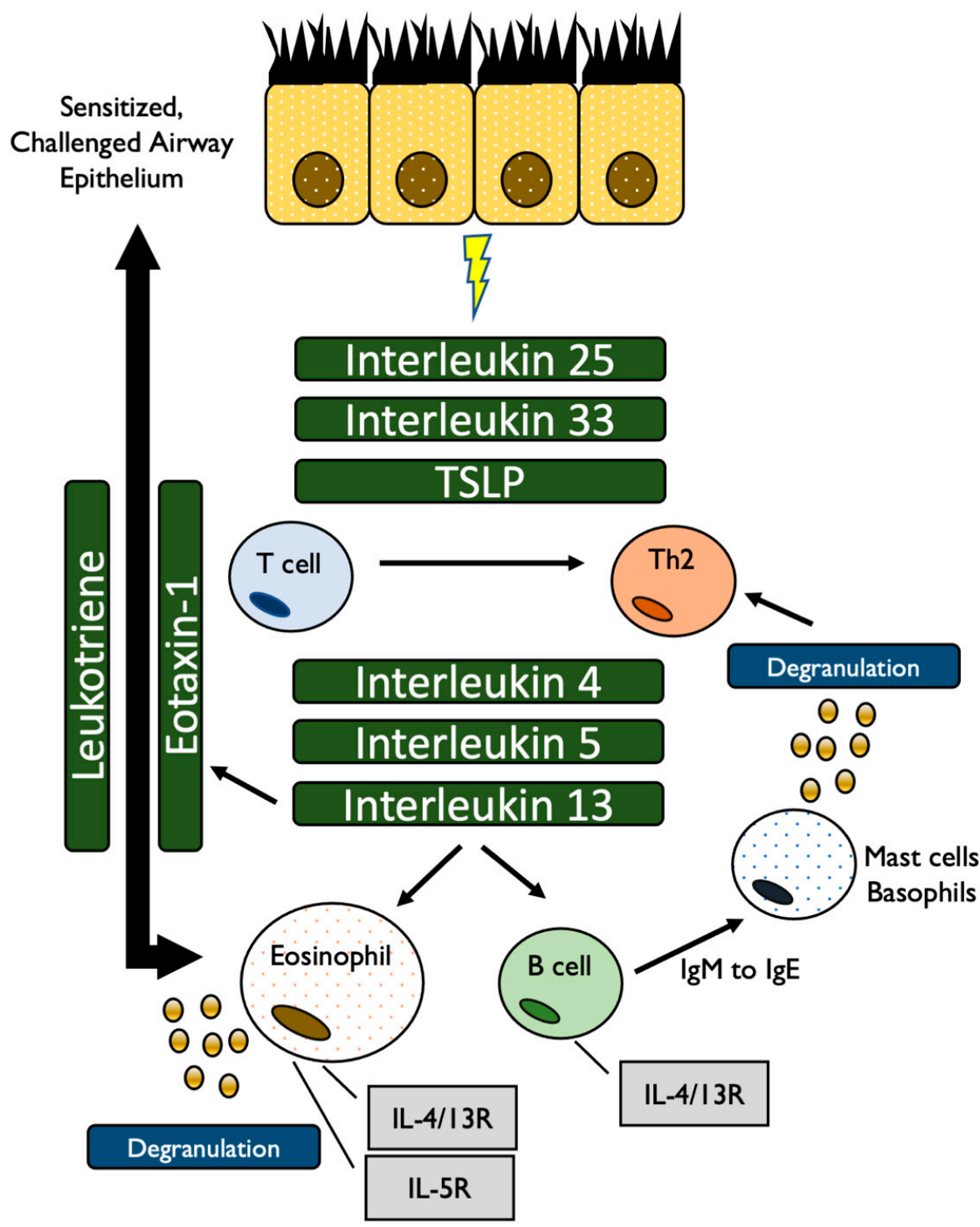

Figure 1. The eosinophil-mediated pathway of asthmatic inflammation [11,12].

Biochemically, allergic asthma is primarily mediated by mast cells, CD4 + T helper- 2 (Th2) cells, and the secretion of interleukin 4 (IL-4), IL-5, and IL-13 [13]. First, T-lymphocytes that are recruited by IL-25, IL-33, and thymic stromal lymphopoietin (TSLP) secreted from challenged epithelium cause the release of Type 2 (T2) cytokines, attracting eosinophils and mast cells within the airway tract [13]. Moreover, these T2-cytokines mediate IL-5 release, which stimulates release of IL-4 and IL-13 by innate lymphoid, CD4+ T, and mast cells (among diverse other types such as basophils and NK T cells), as well as eosinophilic inflammation $[11,13,14]$. IL-4 and IL-13 then cause B-lymphocytes to produce IgE when allergens are detected in the body and, after binding to the IgE receptor (FceR1), 
mucosal mast cells migrate to the bronchus and mediate the inflammatory cytokine cascade comprised of IL-4, IL-5, IL-13, growth factors, neutrophils, histamine, cysteinyl-leukotrienes (Cys-LT), and prostaglandin D2 (PG-D2) [13]. Second, mast cells release proteases such as tryptase and chymase [13]. Tryptase is a mast cell-specific protease that mediates airway hyperresponsiveness whereas chymase activates transforming growth factor- $\beta$ (TGF- $\beta$ ) that initiates airway remodeling [13]. TGF- $\beta$ then triggers the hyperplasia and hypertrophy of smooth muscle cells in the airway while vascular-endothelial growth factor (VEGF) increases the number of blood vessels, narrowing the airway [13]. As a result, plasma leakage from the postcapillary venules causes the airway lumen to swell [13]. Third, large numbers of group 2 innate lymphoid cells (ILC2) are also found in asthma patients and are developmentally controlled by epithelial cytokines such as IL-25, IL-33, and thymic stromal lymphopoietin in addition to TGF- $\beta$ [13] (Figure 1). Lastly, chronic lung inflammation thickens the epithelial layer with stiff collagen III and V through irreversible fibrosis [13]. This collagen deposition, as well as the addition of fibronectin and tenascin C, causes permanent airway fibrosis and, as a consequence, irreversible airway constriction [13, 15]. The cells, secreted cytokines, and targets involved in this pathway are summarized in Table 1.

Table 1. A summary of secretory cells, cytokines, and targets/function. Adapted from Barnes 2017 [13].

\begin{tabular}{ccc}
\hline Cell Type & Secreted Cytokines & Target/Function \\
\hline \multirow{2}{*}{ Th2 } & IL-4 & $\begin{array}{c}\text { Induction of differentiation into Th2 cells } \\
\text { Differentiation of B cells } \\
\text { Enhance IgG and IgE production }\end{array}$ \\
\cline { 2 - 3 } & IL-5 & $\begin{array}{c}\text { Differentiation of B cells } \\
\text { Activation of eosinophils } \\
\text { Stimulate release of IL-4, IL-13 }\end{array}$ \\
\hline Epithelium & IL-13 & $\begin{array}{c}\text { Differentiation of B cells } \\
\text { IgE production }\end{array}$ \\
\cline { 2 - 3 } & TSLP & Control secretion of IL-4, IL-5, IL-13 from ILC2 cells \\
\hline
\end{tabular}

\subsection{Asthma Pathogenesis Factors: Age, Viruses, Bacteria, Genes and Lifestyle}

The mechanism behind asthma pathogenesis varies by subtype, onset age, and mediating illness or allergy. Viral infections at a young age are thought to play an important role in the development of childhood asthma since rhinoviral infection engenders atopic childhood asthma via reductions in interferon- $\beta$ and interferon- $\gamma$ in bronchial epithelial cells $[16,17]$. Respiratory syncytial viruses, human rhinoviruses, human metapneumoviruses, parainfluenza viruses, and coronaviruses are the main respiratory viruses associated with wheezing and asthma exacerbation [18]. Thus, the mechanism behind virally induced asthma is the putative destruction of bronchial epithelial cells via release of pro-inflammatory/pronecrotic cytokines, leading to epithelial cell and tight junction damage [19]. Biologically, relationships between genetic regulatory events, such as DNA methylation of FOX and RUN family genes associated with T cell development, and childhood asthma pathogenesis have been reported [20]. Since the use of eosinophil counts in bronchoalveolar lavage fluid (BALF) from juvenile patients under six years of age with wheezing symptoms were not found to be predictive of asthma, these new genetic approaches might be more predictive of asthma pathogenesis in very young children [21].

Early exposure to bacterial antigens or strains of symbiotic flora in "dirty" environments may also mediate asthmatic development. Two studies, PARSIFAL and GABRJELA, have reported that children living on farms have lower asthma prevalence than children living in the same area but not on farms (adjusted odds ratios of 0.49 and 0.76 , respectively) [22]. Furthermore, the mattress dust surveyed in this study contained more bacteria and a higher variety of fungi for children living on farms than the children from the ref- 
erence group [22]. Another meta-analysis showed similar results where children raised on farms had a $25 \%$ lower asthma rate than children raised on non-farming land [23]. Likewise, the Amish, a population with a traditional farming lifestyle that eschews technology, showed the strongest protection against allergic asthma [23]. Interestingly, whey proteins and microRNA that are included in unprocessed cow milk are also thought to protect children against juvenile asthma development and the ALEX study highlighted the importance of exposure to these allergens during the first years of life [23]. Similarly, the PARSIFAL study expressed the exposure to these allergens during pregnancy is effective to reduce asthma prevalence [23]. Mechanistically, the PARSIFAL study demonstrated how children on farms had high expression of Toll-like receptors, such as IRAK1, IRAK2, and RIPK1 from activated CD4 T helper cells, that are responsible for activating innate immune responses against allergic asthma [23]. Moreover, farm dust increases respiratory epithelial layer barrier capacity via A20 regulation, resulting in a stronger defense against viral infections that drive asthma pathogenesis [23].

Interestingly, not all species of microbes are protective against autoimmune diseases like asthma. Wilson and colleagues reviewed several studies showing that $S$. aureus colonization may enhance the risk of atopic dermatitis (an asthma risk factor) by actively promoting mast cell degranulation, spurring the inflammation that may precipitate other autoimmune reactions [24]. Location may be crucial in this case as S. pneumoniae, $H$. influenzae, and M. catarrhalis colonization of upper airways carries an increased risk of asthma pathogenesis while gut colonization by Faecalibacterium, Lachnospira, Veillonella, and Rothia genera (termed FLVR) within the first 100 days after birth were shown to be protective against asthma [24]. In addition, fungal microorganisms, especially Aspergillus and Pneumocystis spp., have been well reviewed and are known to increase sensitization, exacerbation, and resistance to control among asthmatics [25]. As the mystery behind gut biome-immune interactions are unraveled, more data on the specific genera or species that provide protection against autoimmune diseases could lead to novel targeted therapies with probiotic or microbial supplementation as asthma prophylaxis and treatment.

Despite multiple studies and reviews proving or disproving the protective effect of early pet antigen exposure on asthmatic pathogenesis, there are microbe/immune interactions, environmental mechanisms, and possible individualized interactions that have not been fully delineated. Details of factors that may influence this effect have been extensively reviewed elsewhere [22,23,26-28].

In contrast, the origins for adult-onset asthma are atopy, obesity, aspirin exacerbated respiratory disease (AERD), gastroesophageal reflux disease (GERD), occupation, and smoking [29]. Compared to childhood asthma, adult-onset asthma is more common in females than males, has a smaller remission rate, and less relation between allergy and atopy [29]. Moreover, adult asthma tends to cause heavier lung damage than childhood asthma while progressing much faster [30]. Additionally, adult lifestyle risk factors, such as smoking, stress, pollution, female sex hormones, and occupational irritant exposure, are thought to be contributive [30]. Studies on microbial influence and asthma pathogenesis in adults are limited but promising; a study by Pekkanen and colleagues found that Clostridium cluster XI microbes within the gut were protective against asthma [31]. Again, since the gut flora are an integral part of the immune system, supplementation trials with known immune-modulating and commensal bacteria, such as B. fragilis, S. epidermidis (that counters S. aureus biofilms), and Bifidobacter genera, may provide some protection against pathogenesis or synergistic relief when paired with standard therapies [32].

\section{Overlap with Chronic Obstructive Pulmonary Disorder (COPD)}

\subsection{COPD Pathogenesis}

COPD can be thought of as a progressive decompensation of the pulmonary system due to damage mediated primarily by accumulated exposure to smoke (tobacco or biomass burning), pollution, or some supranormal lung function phenotypes [33]. In particular, cigarette smoking, a key driver of COPD, creates chronic, long-term assault by thou- 
sands of toxic compounds deep within the pulmonary bronchiole network. This recruits sentinel macrophages and neutrophils to the epithelium of the airway, where tertiary lymphoid organs form and T cell-mediated, inflammation-driven airway remodeling (through perforin-mediated alveolar apoptosis and subsequent fibrosis) precipitates emphysema (restricted airflow) as the primary symptom $[33,34]$. This "insidious" sub-clinical inflammation ensures that decades of permanent damage may be inflicted before symptoms are noticed. Catabasis, the resolution and resetting of immune-mediated inflammation, includes lipoxins, resolvins, TGF- $\beta$, and endothelial growth factors, but chronic exposure to smoke or pollution may overwhelm these mechanisms, especially since nicotine paralyzes the lung cilia that would otherwise clear tar and other damaging compounds from the airway [33]. Similarities between asthma and COPD pathogenesis come from the common inflammation and damage of the airway as the respiratory epithelial layer in both COPD and asthma share a common feature of goblet cell metaplasia and squamous cell metaplasia $[35,36]$. However, the chemical mediators stimulated in COPD and asthma differ in that COPD triggers neutrophils, CD8+ T-lymphocytes, macrophages, IL-8, and TNF- $\alpha$ but asthma mediates the release of eosinophils, mast cells, CD4+ T-lymphocytes, macrophages, histamine, IL-4, IL-5, and IL-13 [35].

Some viral pneumoniae, bacterial, or fungal exposures may also lead to COPD pathogenesis as higher $\mathrm{T}$ and $\mathrm{B}$ lymphocyte counts and B cell infiltration into lung tissue could result in generation of autoimmune antibodies against structural components such as elastin or even epithelial cells [33]. In such patients, the secretion of autoantibodies may even target neutrophil granule proteins (e.g., MMP9, CTSH) with secreted IgG, as well as shift targeting by these antibodies to extracellular compartments [37].

Since COPD is irreversible, it may also cause synergistic exacerbation of other lungassociated diseases other than asthma, such as obstructive sleep apnea, allergies, or heart disease [33,38].

\subsection{Asthma-COPD Overlap}

\subsubsection{Overlap in Symptoms and Phenotypes}

Asthma and COPD share several symptoms, namely coughing, shortness of breath, tightness or a feeling of pressure in the chest, and wheezing [38]. However, asthma is distinct in that it is exacerbated by triggers while COPD symptoms are chronic (but may be worse in the morning or at other times) and also include excessive sputum, dyspnea, mouth breathing/gasping, and associated anxiety and depression [39]. Both diseases limit physical activity, daily activities, and have the potential to reduce quality of life unless controlled.

Although symptomatically similar, it is important to remember that asthma arises primarily from mast cell and Th2-mediated inflammation while COPD is induced by lymphocytic infiltration (Th1, Th17, CD4/CD8 T cells) and damage due to environmental exposure [40]. However, the common site of both diseases (lungs) introduces the concept of, statistical overlap with, and treatment strategies of asthma-COPD comorbidity.

\subsubsection{Overlap Statistics}

COPD and asthma comorbidity is known as asthma-COPD-overlap (ACO). ACO patients experience worse exacerbations, lower quality of life, and greater lung damage than with either disease alone [41]. However, while both asthma and COPD are categorized as obstructive pulmonary diseases, asthma airway flow issues are reversible whereas COPD is not [19]. Within Japan, a recent analysis found that, of 30,405 hospitalized patients over the age of $40,2.3 \%$ of ACO, $1.2 \%$ of asthma-only, and $9.7 \%$ of COPD-only patients died from all causes, reflecting a higher severity of COPD in the pulmonary hierarchy of disease [42]. According to The Global Initiative for Asthma and the Global Initiative for Chronic Obstructive Lung Disease, ACO is diagnosed by history of chronic airway disease and the coexistence of both asthma and COPD symptoms [43]. The ACO prevalence worldwide varies from $3.1 \%$ to $55.5 \%$ and, in Japan, it is around $15.4 \%$ to $20.7 \%$ [44]. 
Moreover, a study found that the ACO prevalence in patients that were already diagnosed with asthma was $27.1 \%$ in Japan [44]. This disease status exists in either a COPD-dominant or asthma-dominant form and each may have unique medical, genetic, and environmental causes. A large US study by Diaz-Guzman et al. that compared death rates among ACO, asthma, and COPD sufferers revealed that ACO carried the highest death risk (HR 1.83), followed by COPD alone (HR 1.44) and asthma alone (HR 1.16) [45]. ACO patients are found to have a $13 \%$ higher chance of asthma exacerbation and hospitalization than patients with only asthma or COPD [35]. ACO prevalence in Japan was reported to be higher in men whereas, in some regions, the prevalence was higher in women [44]. This variation may be ascribed to higher use of tobacco products among men, which is the main cause of COPD in Japan [44]. However, biomass smoke, often from agricultural fires, is another causative agent of COPD and may promote ACO pathogenesis in other areas such as North America and Europe [44,46].

\subsubsection{Similarities in $\mathrm{ACO}$ and Asthma Treatment}

Similar treatments are used for ACO and asthma itself as the main treatments for ACO are also the simultaneous use of inhaled corticosteroids (ICS) and long-acting $\beta 2$ agonists (LABA) or long-acting muscarinic antagonists (LAMA) [47]. Additionally, there is a link between juvenile-onset asthma and ACO in that childhood asthma increases the risk of future COPD diagnosis [48]. Of 10,199 smokers, 7\% claimed to have asthma since childhood and, through gene analysis, different gene loci were found that were associated with COPD (IL1RL1, IL13, LINC01149, near GSDMB, and in the C11orf30-LRRC32 region) [48]. This common genetic heritage may be responsible for the beneficial effect of typical asthma treatments on ACO exacerbations. While the divergent pathogenesis mechanisms of asthma and COPD mean that drugs specific for mast cells will not treat COPD, global immunosuppression may relieve the autoantibody-mediated inflammation seen in COPD while preventing asthmatic exacerbations.

\subsubsection{Unique Considerations for ACO Patients}

The differences between adult-onset asthma and ACO, especially the COPD-dominant form, are found in the age of onset, symptoms, reversibility of airway obstruction, and the presence of atopy [49]. Adult-onset asthma has less comorbidity than COPD since COPD is more often comorbid with vascular and lifestyle diseases such as cardiac failure, osteoporosis, obesity, depression, lung cancer, and pneumonia [49]. To distinguish between adult-onset asthma and ACO, medical history, reversibility of airflow, smoking history, response to treatments, and the presence of atopy must be carefully weighed [49]. Additionally, there are differences between COPD-dominant ACO and asthma-dominant ACO. Research conducted by Kim et al. proved that asthma-predominant ACO patients often belong to a lower socioeconomic status and have lower FEV1 and FVC\% (predicted), as well as quality of life, than COPD-predominant ACO patients [50]. Asthma-predominant ACO patients, on the other hand, have a lower hospitalization rate, lower medical costs, and barriers to effective health care than COPD-predominant ACO patients [50].

\section{Diagnosis and Treatment}

\subsection{General Diagnosis and Treatment for Asthma \\ 3.1.1. Diagnostics}

Airflow through the lungs and bronchus is the main criterion for diagnosis and respiratory efficiency thresholds, coupled with signature symptoms, are the gold standards for worldwide diagnosis. In Japan, for example, adult asthma is diagnosed through criteria such as repetitive symptoms of paroxysmal dyspnea, wheezing, chest tightness and cough, reversible airflow limitation, airway hyperresponsiveness, atopy, airway inflammation, and exclusion of other diseases [9]. Reversible airflow limitation is measured by peak expiratory flow (PEF) and FEV1: if FEV1 increases by $12 \%$ or more after administration of a $\beta$-agonist inhaler, the patient is diagnosed as having asthma [9]. Airway hyper-responsiveness is 
tested using nitric oxide (FeNO), acetylcholine, and histamine thresholds while airway inflammation is tested by eosinophil and mast cell counts in sputum [51]. For juvenile-onset asthma, symptoms are similar to adults but there is more emphasis on family history and total serum IgE levels to aid diagnosis [51]. As current diagnostic technology is thought to be sufficient to catch new cases, translational medicine is currently focused on genomic screening to predict prevalence and treatment responses [52,53].

\subsubsection{Treatments}

The current standard treatment worldwide for asthma, as noted in the National Asthma education Prevention Program and in the Global Initiative for Asthma, is a stepwise and measured approach [54]. This protocol starts with corticosteroid inhalers followed by long-acting $\beta$ agonists, leukotriene modifiers, long-acting anticholinergics, and finally oral corticosteroids for the most severe cases [54]. Some research into antihistamines has also been conducted with hopes to inhibit exacerbations but these compounds only seem to be effective in allergic asthma cases [8]. However, recent studies have developed personalized biological and cytokine-specific therapies, derived from antibodies (as denoted by -mab in their generic name), that selectively bind to the $\mathrm{IgE}$ receptor to inhibit its activation and prevent Type 2 asthma attacks [54]. As research progresses, standard management modalities have improved over time and mortality from asthma-related causes is dropping even as morbidity increases. For example, The Vital Statistics of the Japanese Ministry reported a decrease in asthma patient mortality in Japan from 4.5-5.0 per 100,000 patients in 1994 to 1.2 per 100,000 patients in 2016 while, in the US, a decrease in asthma-related mortality from 1999-2015 was seen in all ethnicities and genders for a total rate of 1.5 per 100,000 persons $[55,56]$.

\subsubsection{Biologic Treatments for Asthma and Asthma-COPD-Overlap}

The following section is a survey of the newly developed, targeted therapies being tested for effectiveness in controlling exacerbations. Drugs are listed along with their trade names in the order they were approved by the FDA for asthma [57]. An overview of the direct targets of each compound is available in Figure 2. A recent review by Tu and colleagues suggests that a treatable traits concept, where phenotypic or endotypic features are used to create multi-dimensional biomarker profiles for treatment that can be tested in animal models and this may drive development of newer biologics [58]. A gold-standard analysis of promising ACO treatments (such as macrolides or muscarinic antagonists) has been reviewed by Leung and Sin [59].

\subsection{Compound 1: Omalizumab (Xolair, Approved June, 2003)}

\subsubsection{Mechanism}

Originally developed from a murine source, this IgE-specific human, monoclonal antibody prevents activation of the inflammatory pathway by both neutralizing $\operatorname{IgE}$ and downregulating the IgE receptor on basophils [60]. As free IgE has been known to result from IgG class switching mediated by IL-4 and IL-13, as well as release from allergenstimulated IgE-positive B cells, driving down this response short circuits the activation of mast cells and basophils that activate inflammation and lower T-cell activation thresholds which drive Th2 responses [61]. Omalizumab thus downregulates the sensitization of the immune system through preventing chronic activation of Th2 responses that drive both exacerbation and the histological changes seen in asthmatic airways. 


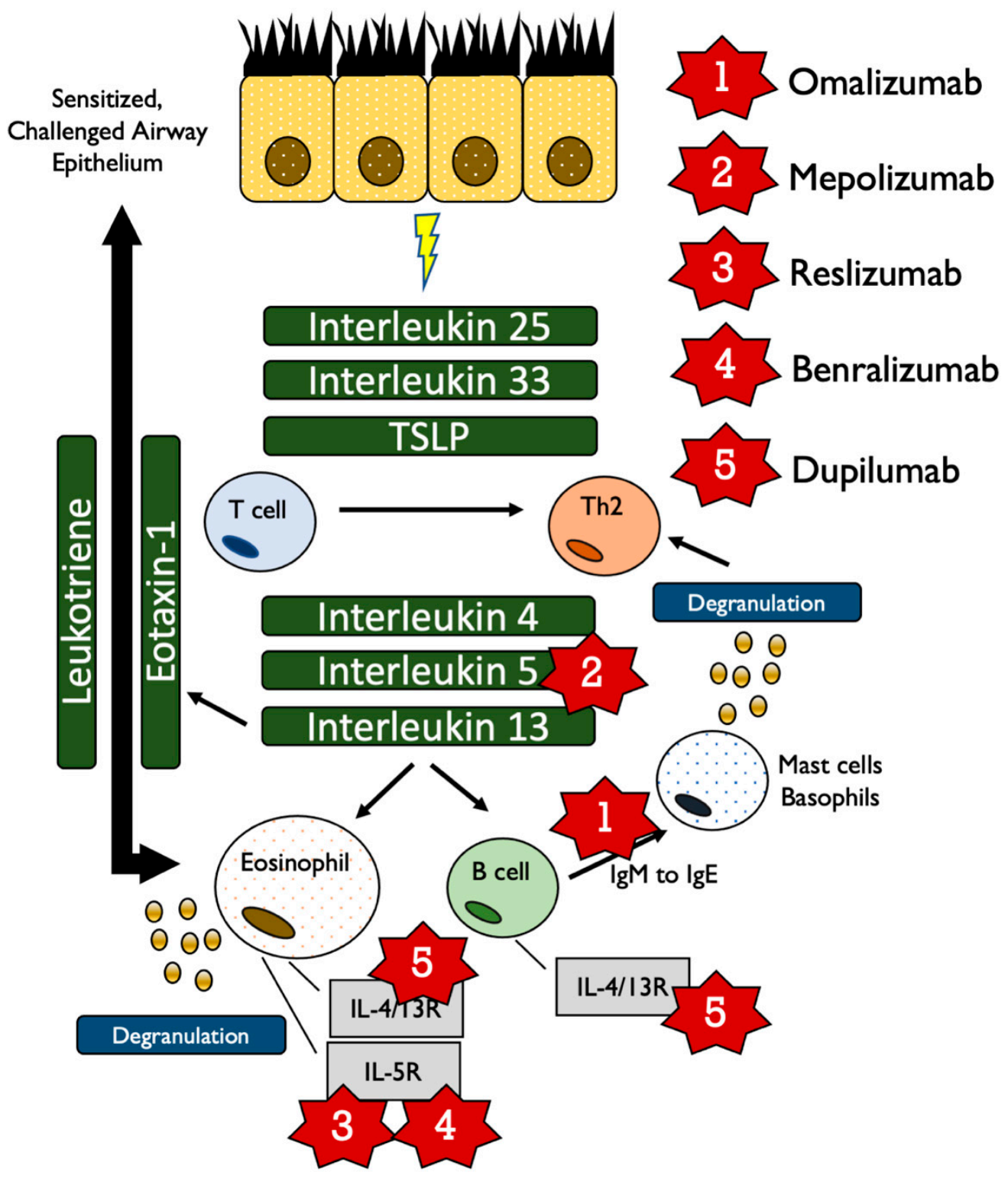

Figure 2. The specific targets of the current generation of biologics within the inflammatory cycle [11,12].

\subsubsection{Asthma Efficacy}

A meta-analysis conducted by the Global Evaluation of Treatment Effectiveness reported that $77 \%$ of severe asthma patients treated with omalizumab had improvement in symptoms after four to six months [62]. In a phase IV clinical trial (Clinicatrials.gov ID: NCT00264849), the use of long-term corticosteroid was reduced $32.3 \%$ more by the addition of omalizumab to optimized asthma treatment (OAT) compared to OAT alone in severe atopic asthma [63]. Omalizumab was also proven effective in non-atopic asthma in a phase IV clinical trial (Clinicatrials.gov ID: NCT01007149) [64]. Patients treated with omalizumab had significant decreases in high affinity IgE receptor (FcERI) and plasmacytoid dendritic cells (pDC2) levels $(p<0.001)$ compared to the placebo group coupled with FEV1 improvements from the baseline by $9.9 \%$ [64].

\subsubsection{ACO Efficacy}

Although omalizumab may hold promise for ACO, an Australian study of the Xolair Registry found that patients with overlapping asthma and COPD had improved asthma control but did not experience improvements in FEV1 or other related parameters [65]. No 
clinical trials using omalizumab specifically for ACO have been reported but several case reports and retrospective studies have shown benefits in these patients [66-68]

\subsection{Compound 2: Mepolizumab (Nucala, Approved November, 2015)}

\subsubsection{Mechanism}

This monoclonal antibody is generated from human N-glycosylated IgG1 kappa chains and was designed to be highly specific to IL-5, neutralizing its binding capacity to IL-5 receptor alpha [69]. As a result, eosinophil maturation is disabled in the bone marrow and eosinophil levels are decreased in blood and bronchial mucus [70]. However, as mepolizumab is highly effective at neutralizing IL-5, immune pathways crucial to antiparasitic response may be compromised, a side effect that must be taken into account within developing countries or pediatric patients [71].

\subsubsection{Asthma Efficacy}

The MENSA study (Clinicaltrials.gov ID: NCT01691521) in 576 patients found a 53\% reduction in exacerbations compared to placebo when administered subcutaneously versus a $47 \%$ reduction via intravenous administration, along with a $100 \mathrm{~mL}$ increase in FEV1 [72]. In mild asthma patients, mepolizumab reduced eosinophils in both the blood and sputum [73]. Likewise, in mild atopic asthma patients, mepolizumab reduced eosinophils in the blood, the bronchoalveolar fluid, and the bone marrow [73]. Mepolizumab is currently registered as a key add-on drug to treat severe eosinophilic asthma for juveniles older than 12 years of age in the United States and for adults in Europe [73]. A retrospective analysis of a French early access program for mepolizumab add-on therapy in cases of severe eosinophilic asthma found that exacerbations of eosinophilic asthma patients, which averaged 5.8 per year, dropped to 0.6 per year after 24 months of follow up along with a significant reduction in primary corticosteroid usage $(92.8 \%$ at baseline vs. $34.7 \%$ after 24 months of follow up) [74]. This effect was also seen in the COSMEX study (Clinicaltrials.gov ID: NCT01691508), where 339 patients received mepolizumab for 2.2 years and found either maintenance of or reductions in oral corticosteroids needed, along with significant reductions in exacerbations [75]. As the primary mode of action is eosinophil depletion, determining the thresholds of eosinophilia that would indicate mepolizumab as suitable for concomitant use is of supreme importance but determining these levels is still controversial [76]. Mepolizumab is also useful regardless of systemic IgE concentration as its local mode of eosinophil control in the airways would lower levels of IgE within the lungs. However, IL-13-mediated pathways would not be affected, as seen in a clinical study that observed no changes in fractional exhaled nitric oxide (FeNO) levels after mepolizumab treatment in 102 patients [77].

\subsubsection{Efficacy and ACO}

The METREX (Clinicaltrials.gov ID: NCT02105948) trial of 836 patients and METREO (Clinicaltrials.gov ID: NCT02105961) trial of 674 patients sought to establish the effect of mepolizumab in preventing COPD exacerbations driven by eosinophilia. METREX found that a $100 \mathrm{mg}$ dose was effective at lowering moderate-to-severe exacerbations of COPD (1.40 per year vs. 1.71 per year in the placebo group) whole METREO also found that $100 \mathrm{mg}$ was most effective in preventing exacerbations (1.19 per year vs. 1.49 per year in the placebo group) [78]. Both trials did not observe severe adverse effects that were significantly different from placebo. A smaller trial of 18 COPD patients with eosinophilic bronchitis, however, found no significant improvements in lung function or exacerbation rates even with significant depletion of sputum eosinophils [79]. However, as the conflicting results indicate, the role of mepolizumab in ACO is suspect as asthma benefits are not seen in the COPD realm, an effect possibly due to the partial role of eosinophils in COPD progression. The FDA, in spite of the METREX and METREO studies, voted against approval of mepolizumab for COPD treatment in 2018 due to questions over the data collection and inability to duplicate the observed efficiencies seen in both studies, noting 
that observed improvements may have been due to asthmatic improvements instead of direct action on COPD [80].

\subsection{Compound 3: Reslizumab (Cinqair, Approved March, 2016)}

\subsubsection{Mechanism}

Reslizumab is a humanized monoclonal antibody IL-5 (mAb) of IgG4 kappa with a high affinity for IL-5 $\alpha$ and a terminal half-life of 24.5 to 30.1 days [73]. Reslizumab functions in severe asthma patients by selectively inhibiting IL- $5 \alpha$ receptors to suppress eosinophil production in the bone marrow [81]. For those COPD patients with eosinophilic-mediated inflammation (around $40 \%$ ), reslizumab may act to reduce risks at eosinophil levels of 300 cells/microliter as reported in the COPDGene and ECLIPSE studies [82].

\subsubsection{Asthma Efficacy}

In a phase III study, reslizumab significantly reduced asthma exacerbations by $54 \%$, improved lung function by $0.11 \mathrm{~L}$, and improved quality of life scores [73]. Pelaia et al. reported that reslizumab significantly increased forced expiratory flow at $25 \%$ to $75 \%$ of forced vital capacity (FEF25-75), proving increased airflow in the peripheral airways [81]. A recently published clinical trial (Clinicaltrials.gov ID: NCT01237039) found that, in 477 asthmatics aged 12-75 years, reslizumab reduced exacerbation risk significantly compared to placebo $(77.5 \%$ reduction in risk vs. $15.2 \%$ in the placebo group) while also reducing primary corticosteroid therapy burden $(254 \mathrm{mg}$ per-patient in the reslizumab group vs. $611 \mathrm{mg}$ per-patient in the placebo group) [83]. Side effects for these clinical trials were all mild to moderate.

\subsubsection{Efficacy and ACO}

No clinical trials have yet been reported for reslizumab efficacy in ACO, but, as ACO places a dual inflammatory burden on the pulmonary system, relieving asthma and reducing medication burden on individual patients may have a beneficial effect in controlling overall ACO impact on quality of life. Additionally, as 20\% of COPD exacerbations are thought to be eosinophil driven, some relief from ACO may be found with reslizumab [82].

\subsection{Compound 4: Benralizumab (Fasenra, Approved November, 2017)}

\subsubsection{Mechanism}

IL-5 stimulates eosinophil production and the recombinant monoclonal antibody benralizumab was created to block the IL- 5 receptor- $\alpha$ to arrest eosinophil differentiation in bone marrow [84]. Unlike other IL-5-neutralizing biologics (reslizumab and mepolizumab), benralizumab directly depletes eosinophils by antibody-dependent cell-mediated cytotoxicity [69] and also binds to NK cells, macrophages, and neutrophils with its heavy chain Fc $\gamma$-receptor $[69,84]$. As a result, eosinophil populations are rapidly reduced (more than 95\%) in both systemic circulation and tissue [84]. However, excessive levels of Type 2 inflammation from inflammatory factors (such as smoking exposure, genotype, gender, age, weight, and comorbidities) may result in poor control of eosinophilic asthma even with benralizumab and cluster analyses to fully define and predict therapy response have been reported [85-87]. Additionally, benralizumab carries no real benefits for non-Type 2-related asthma (non-eosinophil-mediated) and clinicians cannot rely on FeNO and IgE levels to monitor treatment as there have been studies that show no changes in these biomarkers during treatment $[85,86,88]$.

\subsubsection{Asthma Efficacy}

A phase III SIROCCO and CALIMA trial examined 2295 uncontrolled asthma patients treated with corticosteroids and long acting $\beta 2$ agonists (LABA) where one group received $30 \mathrm{mg}$ benralizumab every eight weeks, one received it every four weeks and one received a placebo [89]. Patients that received benralizumab every eight weeks had a $42 \%$ average reduction in exacerbation rates and experienced a $0.14 \mathrm{~L}$ increase in FEV1 compared to 
placebo [89]. Benralizumab was most effective in patients that were on high doses of oral corticosteroids, had polyposis, had a predicted FVC of less than $65 \%$, had more than two exacerbations in the previous year, and were diagnosed after 18 years of age [89]. A different phase III SIROCCO trial that gave benralizumab every four or eight weeks showed how patients with eosinophil counts of more than 300 cells $/ \mu \mathrm{L}$ treated every four weeks experienced an average of $45 \%$ less exacerbations compared to placebo and this reduction was $51 \%$ for the eight-week cohort [90]. Patients who participated in the SIROCCO and CALIMA trials were further studied in the BORA trial over two years to examine the efficacy and safety of benralizumab [91,92]. Patients were either given $30 \mathrm{mg}$ of benralizumab subcutaneously every four or eight weeks and blood eosinophils were counted [91,92]. As a result, $50 \%$ of the patients did not have any exacerbations and the mean prebronchodilator FEV1 increased by $0.310 \mathrm{~L}$ and $0.364 \mathrm{~L}$ in the four-week and eight-week groups [91,92].

\subsubsection{Efficacy and ACO}

Unfortunately, trials with benralizumab in severe ACO have not returned definitive results. A multi-country, phase IIA trial by Brightling et al. in 2014 examined 101 adults, aged 40-85 with severe ACO and found that benralizumab did not significantly reduce COPD exacerbations $(0.95$ [95\%CI $0.68-1.29, n=40$ ] with benralizumab vs. 0.92 [95\%CI $0.67-1.25, n=42$ ] with placebo) but gave some small increases in FEV1 [93]. The recently completed GALATHEA (Clinicaltrials.gov ID: NCT02138916, $n=1656$ ) and TERRANOVA (Clinicaltrials.gov ID: NCT02155660, $n=2255$ ) phase III clinical trials reported in a joint publication that $100 \mathrm{mg}$ benralizumab did not significantly improve exacerbations unless ACO patients had significant elevations in eosinophils [94]. Taken together, benralizumab seems to work only in ACO only when the disease is eosinophil driven. However, it may hold value for asthmatic risk factors, such as atopic dermatitis, and this potential is being tested in several ongoing clinical trials (Clinicaltrials.gov: NCT03563066, NCT04605094).

\subsection{Compound 5: Dupilumab (Dupixent, Approved October, 2018)}

\subsubsection{Mechanism}

Dupilumab, a fully human monoclonal IgG4 antibody that selectively blocks the IL4/IL-13 co-receptor to prevent signal transduction via IL-4R and IL-13, through JAK/STAT6, is used to treat Th2-mediated asthma $[95,96]$. IL-4R triggers IgM to IgE class switching and precipitates a type I allergic reaction and eosinophil infiltration within the airway [95]. IL-13 increases mucus production and inducible nitric oxide synthase (iNOS) in the epithelial cells, mediating airway constriction [95]. Moreover, it promotes goblet cell hyperplasia, which leads to the transformation of bronchial fibroblasts into myofibroblasts [95,96]. Remodeling of the airway with these contractile cells results in the airway hyper responsiveness that is the hallmark of asthma symptoms [95]. Dupilumab thus selectively targets and inhibits a key inflammatory pathway.

\subsubsection{Asthma Efficacy}

A study of 104 asthmatic patients, 52 of whom were treated with dupilumab, saw a $87 \%$ reduction in exacerbation rate compared to placebo [97]. Likewise, dupilumab was found to decrease inflammatory biomarkers such as FeNO concentration, IgE levels (serum, thymus), and activation-regulating chemokines with no serious, drug-related adverse events [97]. In a trial conducted by Rabe et al., 210 asthma patients treated with oral glucocorticoids were randomly chosen to additionally receive either dupilumab or a placebo every two weeks for 24 weeks [98]. The dupilumab patients experienced a $70.1 \%$ decrease in the use of glucocorticoid versus a $41.9 \%$ reduction in the placebo group [98]. Furthermore, there were 30\% more people in the dupilumab group than the placebo group that were able to reduce the amount of glucocorticoid by more than $50 \%$ and their exacerbation rate was $59 \%$ lower [98]. Similar to the studies by Wenzel et al., the dupilumab group also saw an increase in FEV1 of around $200 \mathrm{~mL}[97,98]$. A similar study was outlined 
in a report by Bassani et al., where $69 \%$ of patients that used dupilumab were able to reduce the amount of glucocorticoid to less than $5 \mathrm{mg}$ a day and $48 \%$ were able to stop using glucocorticoids completely [99]. Those patients that were given dupilumab twice a week had a two-fold reduction in severe asthmatic episodes versus placebo [99]. Several human studies were conducted to verify the safety of dupilumab. Rathinam et al. showed that it takes 1 week for $600 \mathrm{mg}$ doses of dupilumab to reach maximum plasma concentration and the bioavailability from subcutaneous injection is around 62.35\% [100]. After reaching therapeutic levels, it takes approximately 10-13 weeks to be eliminated from the body to levels of less than $78 \mathrm{ng} / \mathrm{mL}$ [100]. A phase IIB, multi-dosage trial conducted in 15 countries with 769 patients reported that groups receiving $200 \mathrm{mg}$ and $300 \mathrm{mg}$ of dupilumab every two weeks saw significant increases in FEV1 compared to placebo [100]. In that study, patients that were given dupilumab every two weeks, regardless of dosage, had fewer exacerbations than other groups [100]. As activation mechanisms are shared between atopic dermatitis and asthma, an extensive review by Matsunaga et al. details successful treatment of both diseases with dupilumab, which was recently (2018) approved in Japan for recalcitrant and poorly responding atopic dermatitis and asthma [96].

\subsubsection{Efficacy and ACO}

Dupilumab effectiveness in COPD is currently being studied in the ongoing BOREAS trial (Clinicaltrials.gov ID: NCT03930732) but extensive trials for ACO have not been reported. Dupilumab was found in a clinical trial (Clinicaltrials.gov ID: NCT01312961) to reduce Th2-driven inflammation but has also been reported to increase eosinophils through migration of progenitor cells via IL-4 and IL-13, which may exacerbate COPD symptoms or cause pneumonia $[97,101]$. As such, no current recommendations for dupilumab in ACO have yet been determined.

\section{Discussion}

Asthma prevalence is increasing worldwide even while serious complications and deaths are falling due to innovative new biologic treatments and therapies. With a multifactorial pathogenesis, heterogenous presentation, and long development time, asthma appears to be a disease that must be ameliorated to the fullest extent possible while mechanistic studies are completed that will generate curative therapies. Biologic therapies targeting IL-5 have demonstrated the greatest promise for exacerbation control as evidenced through lower exacerbations (of all severities) and reduced inflammatory biomarkers (eosinophil levels) but adding the complex and not-yet-fully-understood comorbidities of COPD and a lack of solid clinical results has left ACO treatment a complex set of decisions. Future studies will need to address multiple molecular mechanisms simultaneously to determine the best biologic configuration for maximum therapeutic effect. Perhaps high-throughput technologies, such as deep sequencing, proteomics, and metabolomics within the immune and endocrine systems, will provide snapshots of the biochemical and genetic milieu that drive asthma pathogenesis while larger mechanistic studies will detail the progressive deterioration of COPD and its molecular links to asthma exacerbation.

Author Contributions: Conceptualization, M.K. and B.J.M.; data curation, M.K. and B.J.M.; writingoriginal draft preparation, M.K. and B.J.M.; writing—review and editing, M.K. and B.J.M.; supervision, B.J.M.; funding acquisition, B.J.M. All authors have read and agreed to the published version of the manuscript.

Funding: This research received no external funding.

Institutional Review Board Statement: Not applicable due to the review-only nature of the manuscript.

Informed Consent Statement: This review reported only previously published results and, as such, informed consent is not applicable. All reported studies involving humans that were used in this review were confirmed to have informed consent statements. 
Data Availability Statement: Data on reported clinical trials are available from clinicaltrials.gov or their respective publications. No new, unreported datasets were used.

Conflicts of Interest: The authors declare no conflict of interest.

\section{References}

1. Ministry of Health. Labour and Welfare Report: Patient Numbers by Age and Disease; Ministry of Health: Tokyo, Japan, 2017.

2. Yamauchi, Y.I. Epidemiology of Asthma: The Present and Near Future. Nihon Naika Gakkai Zasshi 2018, 107, 2059-2066. [CrossRef]

3. Bush, A. Pathophysiological Mechanisms of Asthma. Front. Pediatr. 2019, 7, 68. [CrossRef] [PubMed]

4. Barnes, P.J. Therapeutic approaches to asthma-chronic obstructive pulmonary disease overlap syndromes. J. Allergy Clin. Immunol. 2015, 136, 531-545. [CrossRef] [PubMed]

5. Agache, I.; Akdis, C.A. Precision medicine and phenotypes, endotypes, genotypes, regiotypes, and theratypes of allergic diseases. J. Clin. Investig. 2019, 129, 1493-1503. [CrossRef] [PubMed]

6. Munekata, T. Adult Asthma: From Phenotype to Endotype (Japanese). Allergy 2017, 66, 9-13.

7. Thangam, E.B.; Jemima, E.A.; Singh, H.; Baig, M.S.; Khan, M.; Mathias, C.B.; Church, M.K.; Saluja, R. The Role of Histamine and Histamine Receptors in Mast Cell-Mediated Allergy and Inflammation: The Hunt for New Therapeutic Targets. Front. Immunol. 2018, 9, 1873. [CrossRef] [PubMed]

8. Yamauchi, K.; Ogasawara, M. The Role of Histamine in the Pathophysiology of Asthma and the Clinical Efficacy of Antihistamines in Asthma Therapy. Int. J. Mol. Sci. 2019, 20, 1733. [CrossRef] [PubMed]

9. Ichinose, M.; Sugiura, H.; Nagase, H.; Yamaguchi, M.; Inoue, H.; Sagara, H.; Tamaoki, J.; Tohda, Y.; Munakata, M.; Yamauchi, K.; et al. Japanese guidelines for adult asthma 2017. Allergol. Int. 2017, 66, 163-189. [CrossRef] [PubMed]

10. Kuruvilla, M.E.; Lee, F.E.-H.; Lee, G.B. Understanding Asthma Phenotypes, Endotypes, and Mechanisms of Disease. Clin. Rev. Allergy Immunol. 2019, 56, 219-233. [CrossRef] [PubMed]

11. Chung, K.F. Targeting the interleukin pathway in the treatment of asthma. Lancet 2015, 386, 1086-1096. [CrossRef]

12. Bakakos, A.; Loukides, S. Severe Eosinophilic Asthma. J. Clin. Med. 2019, 8, 1375. [CrossRef]

13. Barnes, P.J. Cellular and molecular mechanisms of asthma and COPD. Clin. Sci. 2017, 131, 1541-1558. [CrossRef]

14. Junttila, I.S. Tuning the Cytokine Responses: An Update on Interleukin (IL)-4 and IL-13 Receptor Complexes. Front. Immunol. 2018, 9, 888. [CrossRef]

15. Fahy, J.V. Type 2 inflammation in asthma-present in most, absent in many. Nat. Rev. Immunol. 2015, 15, 57-65. [CrossRef] [PubMed]

16. De Benedictis, F.M.; Attanasi, M. Asthma in childhood. Eur. Respir. Rev. 2016, 25, 41-47. [CrossRef] [PubMed]

17. Jayasinghe, H.; Kopsaftis, Z.; Carson, K. Asthma Bronchiale and Exercise-Induced Bronchoconstriction. Respiration 2015, 89, 505-512. [CrossRef] [PubMed]

18. Webley, W.C.; Hahn, D.L. Infection-mediated asthma: Etiology, mechanisms and treatment options, with focus on Chlamydia pneumoniae and macrolides. Respir. Res. 2017, 18, 1-12. [CrossRef]

19. Ekurai, D.; Esaraya, T.; Eishii, H.; Etakizawa, H. Virus-induced exacerbations in asthma and COPD. Front. Microbiol. 2013, 4, 293. [CrossRef]

20. Zheng, X.-Y.; Xu, Y.-J.; Guan, W.-J.; Lin, L.-F. Regional, age and respiratory-secretion-specific prevalence of respiratory viruses associated with asthma exacerbation: A literature review. Arch. Virol. 2018, 163, 845-853. [CrossRef]

21. Gut, G.; Domany, K.A.; Sadot, E.; Soferman, R.; Fireman, E.; Sivan, Y. Eosinophil cell count in bronchoalveolar lavage fluid in early childhood wheezing: Is it predictive of future asthma? J. Asthma 2019, 57, 366-372. [CrossRef] [PubMed]

22. Ege, M.J.; Mayer, M.; Normand, A.-C.; Genuneit, J.; Cookson, W.O.; Braun-Fahrländer, C.; Heederik, D.; Piarroux, R.; Von Mutius, E. Exposure to Environmental Microorganisms and Childhood Asthma. N. Engl. J. Med. 2011, 364, 701-709. [CrossRef] [PubMed]

23. von Mutius, E. The microbial environment and its influence on asthma prevention in early life. J. Allergy Clin. Immunol. 2016, 137, 680-689. [CrossRef] [PubMed]

24. Wilson, N.G.; Hernandez-Leyva, A.; Kau, A.L. The ABCs of wheeze: Asthma and bacterial communities. PLoS Pathog. 2019, 15, e1007645. [CrossRef]

25. Denning, D.W.; Pashley, C.; Hartl, D.; Wardlaw, A.; Godet, C.; Del Giacco, S.; Delhaes, L.; Sergejeva, S. Fungal allergy in asthma-state of the art and research needs. Clin. Transl. Allergy 2014, 4, 14. [CrossRef] [PubMed]

26. Jackson, D.J.; Sykes, A.; Mallia, P.; Johnston, S.L. Asthma exacerbations: Origin, effect, and prevention. J. Allergy Clin. Immunol. 2011, 128, 1165-1174. [CrossRef] [PubMed]

27. Oksel, C.; Custovic, A. Development of allergic sensitization and its relevance to paediatric asthma. Curr. Opin. Allergy Clin. Immunol. 2018, 18, 109-116. [CrossRef]

28. Murrison, L.B.; Brandt, E.B.; Myers, J.B.; Hershey, G.K.K. Environmental exposures and mechanisms in allergy and asthma development. J. Clin. Investig. 2019, 129, 1504-1515. [CrossRef]

29. Scherzer, R.; Grayson, M.H. Heterogeneity and the origins of asthma. Ann. AllergyAsthma Immunol. 2018, 121, 400-405. [CrossRef]

30. De Nijs, S.B.; Venekamp, L.N.; Bel, E.H. Adult-onset asthma: Is it really different? Eur. Respir. Rev. 2013, 22, 44-52. [CrossRef]

31. Pekkanen, J.; Valkonen, M.; Täubel, M.; Tischer, C.; Leppänen, H.; Kärkkäinen, P.M.; Rintala, H.; Zock, J.-P.; Casas, L.; ProbstHensch, N.; et al. Indoor bacteria and asthma in adults: A multicentre case-control study within ECRHS II. Eur. Respir. J. 2018, 51, 1701241. [CrossRef] 
32. Belkaid, Y.; Hand, T.W. Role of the Microbiota in Immunity and Inflammation. Cell 2014, 157, 121-141. [CrossRef]

33. Agustí, A.; Hogg, J.C. Update on the Pathogenesis of Chronic Obstructive Pulmonary Disease. N. Engl. J. Med. 2019, 381, 1248-1256. [CrossRef] [PubMed]

34. Aldonyte, R.; Bagdonas, E.; Raudoniute, J.; Bruzauskaite, I. Novel aspects of pathogenesis and regeneration mechanisms in COPD. Int. J. Chronic Obs. Pulm. Dis. 2015, 10, 995-1013. [CrossRef] [PubMed]

35. Cosío, B.G.; DaCal, D.; De Llano, L.P. Asthma-COPD overlap: Identification and optimal treatment. Adv. Respir. Dis. 2018, 12, 175346661880566. [CrossRef] [PubMed]

36. Van Tho, N.; Park, H.Y.; Nakano, Y. Asthma-COPD overlap syndrome (ACOS): A diagnostic challenge. Respirology 2015, 21, 410-418. [CrossRef]

37. Ma, A.; Wen, L.; Yin, J.; Hu, Y.; Yue, X.; Li, J.; Dong, X.; Gupta, Y.; Ludwig, R.J.; Krauss-Etschmann, S.; et al. Serum Levels of Autoantibodies Against Extracellular Antigens and Neutrophil Granule Proteins Increase in Patients with COPD Compared to Non-COPD Smokers. Int. J. Chronic Obs. Pulm. Dis. 2020, 15, 189-200. [CrossRef] [PubMed]

38. Owens, R.L.; Macrea, M.M.; Teodorescu, M. The overlaps of asthma or COPD with OSA: A focused review. Respirology 2017, 22, 1073-1083. [CrossRef]

39. Miravitlles, M.; Ribera, A. Understanding the impact of symptoms on the burden of COPD. Respir. Res. 2017, 18, 1-11. [CrossRef]

40. Rogliani, P.; Ora, J.; Puxeddu, E.; Cazzola, M. Airflow obstruction: Is it asthma or is it COPD? Int. J. Chronic Obs. Pulm. Dis. 2016, 11, 3007-3013. [CrossRef]

41. Llanos, J.-P.; Ortega, H.; Germain, G.; Duh, M.S.; Lafeuille, M.-H.; Tiggelaar, S.; Bell, C.F.; Hahn, B. Health characteristics of patients with asthma, COPD and asthma-COPD overlap in the NHANES database. Int. J. Chronic Obs. Pulm. Dis. 2018, 13, 2859-2868. [CrossRef] [PubMed]

42. Yamauchi, Y.; Yasunaga, H.; Matsui, H.; Hasegawa, W.; Jo, T.; Takami, K.; Fushimi, K.; Nagase, T. Comparison of in-hospital mortality in patients with COPD, asthma and asthma-COPD overlap exacerbations. Respirology 2015, 20, 940-946. [CrossRef]

43. Yanagisawa, S.; Ichinose, M. Definition and diagnosis of asthma-COPD overlap (ACO). Allergol. Int. 2018, 67, 172-178. [CrossRef]

44. Uchida, A.; Sakaue, K.; Inoue, H. Epidemiology of asthma-chronic obstructive pulmonary disease overlap (ACO). Allergol. Int. 2018, 67, 165-171. [CrossRef] [PubMed]

45. Diaz-Guzman, E.; Khosravi, M.; Mannino, D.M. Asthma, Chronic Obstructive Pulmonary Disease, and Mortality in the U.S. Population. Copd J. Chronic Obs. Pulm. Dis. 2011, 8, 400-407. [CrossRef] [PubMed]

46. Golpe, R.; Martín-Robles, I.; Sanjuán-López, P.; Pérez-De-Llano, L.; González-Juanatey, C.; López-Campos, J.L.; Arellano-Orden, E. Differences in systemic inflammation between cigarette and biomass smoke-induced COPD. Int. J. Chronic Obs. Pulm. Dis. 2017, 12, 2639-2646. [CrossRef] [PubMed]

47. Kondo, M.; Tamaoki, J. Therapeutic approaches of asthma and COPD overlap. Allergol. Int. 2018, 67, 187-190. [CrossRef] [PubMed]

48. Hayden, L.P.; on behalf of the COPDGene Investigators; Cho, M.H.; Raby, B.A.; Beaty, T.H.; Silverman, E.K.; Hersh, C.P. Childhood asthma is associated with COPD and known asthma variants in COPDGene: A genome-wide association study. Respir. Res. 2018, 19, 209. [CrossRef] [PubMed]

49. Abramson, M.J.; Perret, J.L.; Dharmage, S.C.; McDonald, V.M.; McDonald, C.F. Distinguishing adult-onset asthma from COPD: A review and a new approach. Int. J. Chronic Obs. Pulm. Dis. 2014, 9, 945. [CrossRef]

50. Kim, M.-H.; Rhee, C.K.; Kim, K.; Kim, S.H.; Lee, J.Y.; Kim, Y.H.; Yoo, K.H.; Cho, Y.-J.; Jung, K.-S.; Lee, J.H. Heterogeneity of asthma and COPD overlap. Int. J. Chronic Obs. Pulm. Dis. 2018, 13, 1251-1260. [CrossRef] [PubMed]

51. Arakawa, H.; Hamasaki, Y.; Kohno, Y.; Ebisawa, M.; Kondo, N.; Nishima, S.; Nishimuta, T.; Morikawa, A. Japanese guidelines for childhood asthma 2017. Allergol. Int. 2017, 66, 190-204. [CrossRef]

52. Hernandez-Pacheco, N.; Pino-Yanes, M.; Flores, C. Genomic Predictors of Asthma Phenotypes and Treatment Response. Front. Pediatr. 2019, 7, 6. [CrossRef]

53. Huo, Y.; Zhang, H.-Y. Genetic Mechanisms of Asthma and the Implications for Drug Repositioning. Genes 2018, 9, 237. [CrossRef] [PubMed]

54. Wechsler, E.M. Current and Emerging Biologic Therapies for Asthma and COPD. Respir. Care 2018, 63, 699-707. [CrossRef]

55. Nagase, H. Severe asthma in Japan. Allergol. Int. 2019, 68, 167-171. [CrossRef] [PubMed]

56. Pennington, E.; Yaqoob, Z.J.; Al-Kindi, S.G.; Zein, J. Trends in Asthma Mortality in the United States: 1999 to 2015. Am. J. Respir. Crit. Care Med. 2019, 199, 1575-1577. [CrossRef] [PubMed]

57. Available online: drugs.comhttps:/ / www.drugs.com/history-f1.html (accessed on 8 February 2021).

58. Tu, X.; Donovan, C.; Kim, R.Y.; Wark, P.A.; Horvat, J.C.; Hansbro, P.M. Asthma-COPD overlap: Current understanding and the utility of experimental models. Eur. Respir. Rev. 2021, 30, 190185. [CrossRef]

59. Leung, J.M.; Sin, D.D. Asthma-COPD overlap syndrome: Pathogenesis, clinical features, and therapeutic targets. BMJ 2017, 358, j3772. [CrossRef] [PubMed]

60. Godse, K.; Mehta, A.; Patil, S.; Gautam, M.; Nadkarni, N. Omalizumab-A review. Indian J. Derm. 2015, 60, 381-384. [CrossRef] [PubMed]

61. Froidure, A.; Mouthuy, J.; Durham, S.R.; Chanez, P.; Sibille, Y.; Pilette, C. Asthma phenotypes and IgE responses. Eur. Respir. J. 2015, 47, 304-319. [CrossRef] 
62. Okayama, Y.; Matsumoto, H.; Odajima, H.; Takahagi, S.; Hide, M.; Okubo, K. Roles of omalizumab in various allergic diseases. Allergol. Int. 2020, 69, 167-177. [CrossRef] [PubMed]

63. Siergiejko, Z.; Świebocka, E.; Smith, N.; Peckitt, C.; Leo, J.; Peachey, G.; Maykut, R. Oral corticosteroid sparing with omalizumab in severe allergic (IgE-mediated) asthma patients. Curr. Med. Res. Opin. 2011, 27, 2223-2228. [CrossRef]

64. Garcia, G.; Magnan, A.; Chiron, R.; Contin-Bordes, C.; Berger, P.; Taillé, C.; Devouassoux, G.; De Blay, F.; Couderc, L.-J.; Didier, A.; et al. A Proof-of-Concept, Randomized, Controlled Trial of Omalizumab in Patients with Severe, Difficult-to-Control, Nonatopic Asthma. Chest 2013, 144, 411-419. [CrossRef] [PubMed]

65. Maltby, S.; Gibson, P.G.; Powell, H.; McDonald, V.M. Omalizumab Treatment Response in a Population with Severe Allergic Asthma and Overlapping COPD. Chest 2017, 151, 78-89. [CrossRef] [PubMed]

66. Tat, T.S.; Cilli, A. Omalizumab treatment in asthma-COPD overlap syndrome. J. Asthma 2016, 53, 1048-1050. [CrossRef]

67. Hanania, N.A.; Chipps, B.E.; Griffin, N.M.; Yoo, B.; Iqbal, A.; Casale, T.B. Omalizumab effectiveness in asthma-COPD overlap: Post hoc analysis of PROSPERO. J. Allergy Clin. Immunol. 2019, 143, 1629-1633.e2. [CrossRef]

68. Kupryś-Lipinska, I.; Pałczyński, C.; Molinska, J.; Kuna, P. Omalizumab therapy in a patient with severe asthma and co-existing chronic obstructive pulmonary disease. Adv. Derm. Allergol. 2019, 36, 239-241. [CrossRef] [PubMed]

69. Menzella, F.; Lusuardi, M.; Galeone, C.; Facciolongo, N.; Zucchi, L. The clinical profile of benralizumab in the management of severe eosinophilic asthma. Adv. Respir. Dis. 2016, 10, 534-548. [CrossRef] [PubMed]

70. Faverio, P.; Bonaiti, G.; Bini, F.; Vaghi, A.; Pesci, A. Mepolizumab as the first targeted treatment for eosinophilic granulomatosis with polyangiitis: A review of current evidence and potential place in therapy. Clin. Risk Manag. 2018, 14, 2385-2396. [CrossRef] [PubMed]

71. Giovannini, M.; Mori, F.; Barni, S.; De Martino, M.; Novembre, E. Omalizumab and mepolizumab in the landscape of biological therapy for severe asthma in children: How to choose? Ital. J. Pediatr. 2019, 45, 1-9. [CrossRef]

72. Ortega, H.G.; Liu, M.C.; Pavord, I.D.; Brusselle, G.G.; Fitzgerald, J.M.; Chetta, A.; Humbert, M.; Katz, L.E.; Keene, O.N.; Yancey, S.W.; et al. Mepolizumab Treatment in Patients with Severe Eosinophilic Asthma. N. Engl. J. Med. 2014, 371, 1198-1207. [CrossRef]

73. Nixon, J.; Newbold, P.; Mustelin, T.; Anderson, G.P.; Kolbeck, R. Monoclonal antibody therapy for the treatment of asthma and chronic obstructive pulmonary disease with eosinophilic inflammation. Pharmacol. Ther. 2017, 169, 57-77. [CrossRef]

74. Taillé, C.; Chanez, P.; Devouassoux, G.; Didier, A.; Pison, C.; Garcia, G.; Charriot, J.; Bouée, S.; Gruber, A.; Pribil, C.; et al. Mepolizumab in a population with severe eosinophilic asthma and corticosteroid dependence: Results from a French early access programme. Eur. Respir. J. 2020, 55, 1902345. [CrossRef]

75. Khurana, S.; Brusselle, G.G.; Bel, E.H.; FitzGerald, J.M.; Masoli, M.; Korn, S.; Kato, M.; Albers, F.C.; Bradford, E.S.; Gilson, M.J.; et al. Long-term Safety and Clinical Benefit of Mepolizumab in Patients With the Most Severe Eosinophilic Asthma: The COSMEX Study. Clin. Ther. 2019, 41, 2041-2056.e5. [CrossRef] [PubMed]

76. Emma, R.; Morjaria, J.B.; Fuochi, V.; Polosa, R.; Caruso, M. Mepolizumab in the management of severe eosinophilic asthma in adults: Current evidence and practical experience. Adv. Respir. Dis. 2018, 12, 1753466618808490. [CrossRef] [PubMed]

77. Jackson, D.; Shackshaft, L.; Green, L.; Roxas, C.; Fernandes, M.; Thompson, L.; D'Ancona, G.; Elstad, M.; Douiri, A.; Nanzer-Kelly, A.; et al. The relationship between fractional exhaled nitric oxide and asthma symptom scores in patients on mepolizumab. In Monitoring Airway Disease; European Respiratory Society (ERS): Lausanne, Switzerland, 2019; Volume 54, p. 2623.

78. Pavord, I.D.; Chanez, P.; Criner, G.J.; Kerstjens, H.A.; Korn, S.; Lugogo, N.; Martinot, J.-B.; Sagara, H.; Albers, F.C.; Bradford, E.S.; et al. Mepolizumab for Eosinophilic Chronic Obstructive Pulmonary Disease. N. Engl. J. Med. 2017, 377, 1613-1629. [CrossRef] [PubMed]

79. Dasgupta, A.; Kjarsgaard, M.; Capaldi, D.; Radford, K.; Aleman, F.; Parraga, G.; Altman, L.; Wight, T.; O’Byrne, P.M.; Nair, P. Mepolizumab in COPD with eosinophilic bronchitis: A randomized clinical trial. In 5.1 Airway Pharmacology and Treatment; European Respiratory Society (ERS): Lausanne, Switzerland, 2016; Volume 48, p. PA305.

80. Inserro, A. AJMC.com. Available online: https://www.ajmc.com/view/fda-advisory-committee-votes-against-approvingmepolizumab-for-copd (accessed on 8 February 2021).

81. Pelaia, C.; Paoletti, G.; Puggioni, F.; Racca, F.; Pelaia, G.; Canonica, G.W.; Heffler, E. Interleukin-5 in the Pathophysiology of Severe Asthma. Front. Physiol. 2019, 10, 1514. [CrossRef] [PubMed]

82. Narendra, D.K.; Hanania, N.A. Targeting IL-5 in COPD. Int. J. Chronic Obs. Pulm. Dis. 2019, 14, 1045-1051. [CrossRef]

83. Nair, P.; Bardin, P.; Humbert, M.; Murphy, K.R.; Hickey, L.; Garin, M.; VanLandingham, R.; Chanez, P. Efficacy of Intravenous Reslizumab in Oral Corticosteroid-Dependent Asthma. J. Allergy Clin. Immunol. Pr. 2020, 8, 555-564. [CrossRef] [PubMed]

84. González, I.D.; Benítez, F.M.; Quirce, S. Benralizumab: A New Approach for the Treatment of Severe Eosinophilic Asthma. J. Investig. Allergol. Clin. Immunol. 2019, 29, 84-93. [CrossRef]

85. Izumo, T.; Tone, M.; Kuse, N.; Awano, N.; Tanaka, A.; Jo, T.; Yoshimura, H.; Minami, J.; Takada, K.; Inomata, M. Effectiveness and safety of benralizumab for severe asthma in clinical practice (J-BEST): A prospective study. Ann. Transl. Med. 2020, 8, 438. [CrossRef] [PubMed]

86. Tanosaki, T.; Kabata, H.; Matsusaka, M.; Miyata, J.; Masaki, K.; Mochimaru, T.; Okuzumi, S.; Kuwae, M.; Watanabe, R.; Suzuki, Y.; et al. Clinical characteristics of patients with not well-controlled severe asthma in Japan: Analysis of the Keio Severe Asthma Research Program in Japanese population (KEIO-SARP) registry. Allergol. Int. 2020, 70. [CrossRef] [PubMed] 
87. Nakajima, M.; Matsuyama, M.; Arai, N.; Yamada, H.; Hyodo, K.; Nonaka, M.; Kitazawa, H.; Yoshida, K.; Shigemasa, R.; Morishima, Y.; et al. Identification of whole blood gene expressions correlated with responsiveness to benralizumab. J. Allergy Clin. Immunol. 2021, 147, 772-775. [CrossRef] [PubMed]

88. Busse, W.W. Biological treatments for severe asthma: A major advance in asthma care. Allergol. Int. 2019, 68, 158-166. [CrossRef]

89. Bleecker, E.R.; Wechsler, M.E.; Fitzgerald, J.M.; Menzies-Gow, A.; Wu, Y.; Hirsch, I.; Goldman, M.; Newbold, P.; Zangrilli, J.G. Baseline patient factors impact on the clinical efficacy of benralizumab for severe asthma. Eur. Respir. J. 2018, 52, 1800936. [CrossRef]

90. Maselli, D.J.; Rogers, L.I.; Peters, J. Benralizumab, an add-on treatment for severe eosinophilic asthma: Evaluation of exacerbations, emergency department visits, lung function, and oral corticosteroid use. Clin. Risk Manag. 2018, 14, 2059-2068. [CrossRef] [PubMed]

91. Busse, W.W.; Bleecker, E.R.; FitzGerald, J.M.; Ferguson, G.T.; Barker, P.; Sproule, S.; Olsson, R.F.; Martin, U.J.; Goldman, M.; Yañez, A.; et al. Long-term safety and efficacy of benralizumab in patients with severe, uncontrolled asthma: 1-year results from the BORA phase 3 extension trial. Lancet Respir. Med. 2019, 7, 46-59. [CrossRef]

92. Fitzgerald, J.M.; Bleecker, E.R.; Bourdin, A.; Busse, W.W.; Ferguson, G.T.; Brooks, L.; Barker, P.; Martin, U.J. Two-Year Integrated Efficacy And Safety Analysis Of Benralizumab In Severe Asthma. J. Asthma Allergy 2019, 12, 401-413. [CrossRef]

93. Brightling, C.E.; Bleecker, E.R.; Panettieri, R.A., Jr.; Bafadhel, M.; She, D.; Ward, C.K.; van der Merwe, R. Benralizumab for chronic obstructive pulmonary disease and sputum eosinophilia: A randomised, double-blind, placebo-controlled, phase 2a study. Lancet Respir. Med. 2014, 2, 891-901. [CrossRef]

94. Criner, G.J.; Celli, B.R.; Singh, D.; Agusti, A.; Papi, A.; Jison, M.; Makulova, N.; Shih, V.H.; Brooks, L.; Barker, P.; et al. Predicting response to benralizumab in chronic obstructive pulmonary disease: Analyses of GALATHEA and TERRANOVA studies. Lancet Respir. Med. 2020, 8, 158-170. [CrossRef]

95. Barranco, P.; Phillips-Angles, E.; Dominguez-Ortega, J.; Quirce, S. Dupilumab in the management of moderate-to-severe asthma: The data so far. Clin. Risk Manag. 2017, 13, 1139-1149. [CrossRef]

96. Matsunaga, K.; Katoh, N.; Fujieda, S.; Izuhara, K.; Oishi, K. Dupilumab: Basic aspects and applications to allergic diseases. Allergol. Int. 2020, 69, 187-196. [CrossRef] [PubMed]

97. Wenzel, S.; Ford, L.; Pearlman, D.; Spector, S.; Sher, L.; Skobieranda, F.; Wang, L.; Kirkesseli, S.; Rocklin, R.; Bock, B.; et al. Dupilumab in Persistent Asthma with Elevated Eosinophil Levels. N. Engl. J. Med. 2013, 368, 2455-2466. [CrossRef] [PubMed]

98. Rabe, K.F.; Nair, P.; Brusselle, G.; Maspero, J.F.; Castro, M.; Sher, L.; Zhu, H.; Hamilton, J.D.; Swanson, B.N.; Khan, A.; et al. Efficacy and Safety of Dupilumab in Glucocorticoid-Dependent Severe Asthma. N. Engl. J. Med. 2018, 378, 2475-2485. [CrossRef]

99. Bassani, C.; Rossi, L.; Siveris, K.; Sferelli, R.L.; Saraiva, L.; Tanno, L.K. Use of dupilumab on the treatment of moderate-to-severe asthma: A systematic review. Rev. Da Assoc. Méd. Bras. 2019, 65, 1223-1228. [CrossRef]

100. Rathinam, K.K.; Abraham, J.J.; Vijayakumar, T.M. Dupilumab in the Treatment of Moderate to Severe Asthma: An Evidence-Based Review. Curr. Res. 2019, 91, 45-51. [CrossRef]

101. Caminati, M.; Menzella, F.; Guidolin, L.; Senna, G. Targeting eosinophils: Severe asthma and beyond. Drugs Context 2019, 8 , 212587. [CrossRef] [PubMed] 